\title{
Effect of preoperative pregabalin in video-assisted thoracoscopic surgery
}

\author{
Noriyuki Matsutani ${ }^{1}$, Nobuhiko Seki ${ }^{2}$ \\ ${ }^{1}$ Department of Surgery, Teikyo University Hospital, Mizonokuchi, Kanagawa, Japan; ${ }^{2}$ Department of Internal Medicine, Teikyo University School \\ of Medicine, Tokyo, Japan \\ Correspondence to: Noriyuki Matsutani, MD. Department of Surgery, Teikyo University Hospital, 5-1-1 Futako Takatsu-ku Kawasaki-city, Kanagawa \\ 213-8507, Japan. Email: matsutani1970@yahoo.co.jp. \\ Provenance: This is an invited Editorial commissioned by the Section Editor Laura Chiara Guglielmetti (Cantonal Hospital Winterthur, Kantonsspital \\ Winterthur, Winterthur, Switzerland). \\ Comment on: Kim JC, Byun S, Kim S, et al. Effect of preoperative pregabalin as an adjunct to a multimodal analgesic regimen in video-assisted \\ thoracoscopic surgery: A randomized controlled trial. Medicine (Baltimore) 2017;96:e8644.
}

Submitted Sep 04, 2018. Accepted for publication Sep 11, 2018.

doi: $10.21037 /$ jtd.2018.09.82

View this article at: http://dx.doi.org/10.21037/jtd.2018.09.82

Severe postoperative pain develops with high frequency in $40-80 \%$ of patients after thoracic surgery (1-4). The pain is usually caused by factors such as inflammation of the pleura, intercostal damage, and iatrogenic rib fracture (5). Postoperative pain consists of nociceptive pain and neuropathic pain (6). Nociceptive pain is the pain derived from stimulation of nociceptors due to inflammation caused by surgical procedures such as incisions and sutures. It has been known that nociceptive pain can be effectively treated with NSAIDs (6). On the other hand, neuropathic pain occurs due to intercostal nerve damage. Epidural blocks, which block nerve circuits, and pregabalin, which suppresses release of neurotransmitters by binding to $\mathrm{Ca}^{2+}$ channels at the presynapse of the nerve, are known to be effective to treat neuropathic pain (3,7-10) (Figure 1).

The treatment goals for postoperative pain are to decrease opioid consumption, control acute postsurgical pain, and minimize the incidence of chronic pain $(6,11)$. To achieve these goals, it is important to use analgesics with different action mechanisms to give maximal pain relief with minimal adverse effects. Moreover, inhibition of the establishment of peripheral and central sensitization, which results in amplification and prolongation of pain, is also important (12). Performing minimal invasive surgery should be taken into consideration as one action for analgesic effect (13) (Table 1).

\section{Analgesic options for thoracic surgery}

Local analgesia techniques, systemic analgesia, and analgesic adjuncts are known as analgesic options $(6,11,12,14)$. By applying these various analgesics with different action mechanisms, postoperative analgesia can be obtained with opioid-sparing effects.

There are various procedures in local analgesia techniques including thoracic epidural, paravertebral block, intrathecal opioids, intercostal nerve block, intrapleural analgesia, and wound infiltration (11). Thoracic epidural is the gold standard for pain management during the perioperative period for patients undergoing thoracic surgery; however, the procedure can be followed by the technique-related complications as well as the limitations for use in patients receiving anti-coagulants $(10,15-18)$.

Acetaminophen, nonsteroidal anti-inflammatory drugs (7), cyclooxygenase-2 (14) specific inhibitors, and opioids are used for systemic analgesia (14). Opioids are widely used as intravenous patient-controlled analgesia (13) for their high effectiveness and convenience. However, opioids can cause adverse effects such as respiratory depression, sedation, nausea, vomiting, and constipation which are problematic; thus, they can prevent early recovery of patients after surgery and reduce patient satisfaction. In pain control after surgery, opioid-free effect is anticipated to have effectiveness 


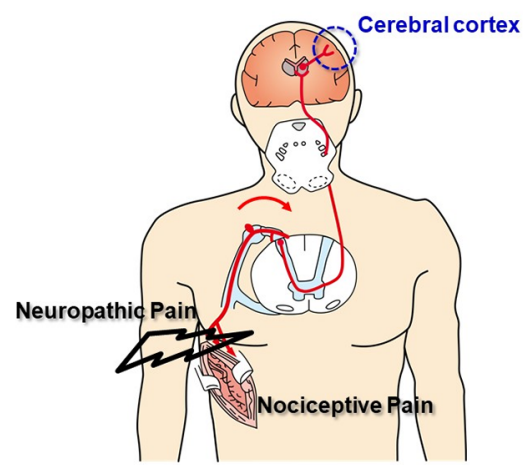

Figure 1 Schema of the pain route in thoracic surgery. Epidural block and pregabalin can act on the posterior horn of the spinal cord and show effectiveness for neuropathic pain [Taken from reference 9 after modification] (9).

not only in short-term prognosis improvement but also in long-term prognosis improvement. Today, as multimodal approaches have become mainstream in analgesia, it is necessary to have a thorough knowledge regarding nonopioid drugs (6).

Steroids, ketamine, and gabapentinoids are used for analgesic adjuncts (14). Gabapentin and pregabalin are members of the gabapentinoids and are used for postoperative pain management in various surgeries (19-21). Compared to gabapentin, pregabalin is considered more effective as it is absorbed more quickly and shows higher biological activity $(22,23)$.

Pregabalin showed effectiveness equal to or more effective than epidural analgesia in treating postthoracotomy pain (10). In recent years, pregabalin is being considered for preemptive use $(13,19)$.

\section{Preemptive analgesia}

Hyperalgesia and tactile allodynia, which cause prolonging of postoperative pain, are known to be triggered by surgical trauma. Establishment of peripheral and central sensitization are involved in the amplification and prolongation of pain; therefore, inhibition of the establishment of these sensitizations is important for preventing postoperative pain $(21,24,25)$. From this perspective, postoperative pain can be reduced by preemptive analgesia, which suppresses the pain circuit, before injury-induced hypersensitivity is established. In various surgeries, the effectiveness of preemptive analgesia has been reported $(13,19,20)$. In video-assisted thoracoscopic surgery (VATS), preemptive administration
Table 1 Managing postoperative pain $(6,11,12)$

\begin{tabular}{l}
\hline Treatment goals \\
Decrease opioid use \\
Control acute postsurgical pain \\
Minimize incidence of chronic pain \\
Potential tools \\
Multimodal analgesia \\
Local analgesia \\
Systemic analgesia \\
Minimally invasive surgery
\end{tabular}

of pregabalin reduced the amount of opioid use while retaining analgesic effectiveness (13).

\section{Conclusions}

Multimodal analgesia in thoracic surgery is effective in increasing analgesic effectiveness and reducing opioidrelated adverse effects. In VATS, preemptive administration of pregabalin is effective.

\section{Acknowledgements}

None.

\section{Footnote}

Conflicts of Interest: The authors have no conflicts of interest to declare.

\section{References}

1. Steegers MA, Snik DM, Verhagen AF, et al. Only half of the chronic pain after thoracic surgery shows a neuropathic component. J Pain 2008;9:955-61.

2. Dajczman E, Gordon A, Kreisman H, et al. Long-term postthoracotomy pain. Chest 1991;99:270-4.

3. Williams EH, Williams CG, Rosson GD, et al. Neurectomy for treatment of intercostal neuralgia. Ann Thorac Surg 2008;85:1766-70.

4. Rogers ML, Henderson L, Mahajan RP, et al. Preliminary findings in the neurophysiological assessment of intercostal nerve injury during thoracotomy. Eur J Cardiothorac Surg 2002;21:298-301. 
5. Elmore B, Nguyen V, Blank R, et al. Pain Management Following Thoracic Surgery. Thorac Surg Clin 2015;25:393-409.

6. Kehlet H, Jensen TS, Woolf CJ. Persistent postsurgical pain: risk factors and prevention. Lancet 2006;367:1618-25.

7. Matsutani N, Dejima H, Takahashi Y, et al. Pregabalin reduces post-surgical pain after thoracotomy: a prospective, randomized, controlled trial. Surg Today 2015;45:1411-6.

8. Matsutani N, Kawamura M. Significant improvement of chronic pain by Pregabalin after thoracotomy: report of four cases. Surg Today 2013;43:915-7.

9. Matsutani N, Kawamura M. Successful management of postoperative pain with pregabalin after thoracotomy. Surg Today 2014;44:712-5.

10. Matsutani N, Yamane H, Suzuki T, et al. Pregabalin as an analgesic option for patients undergoing thoracotomy: cost analysis of pregabalin versus epidural analgesia for postthoracotomy pain relief. J Thorac Dis 2018;10:2321-30.

11. Rivat C, Bollag L, Richebe P. Mechanisms of regional anaesthesia protection against hyperalgesia and pain chronicization. Curr Opin Anaesthesiol 2013;26:621-5.

12. Brulotte V, Ruel MM, Lafontaine E, et al. Impact of pregabalin on the occurrence of postthoracotomy pain syndrome: a randomized trial. Reg Anesth Pain Med 2015;40:262-9.

13. Kim JC, Byun S, Kim S, et al. Effect of preoperative pregabalin as an adjunct to a multimodal analgesic regimen in video-assisted thoracoscopic surgery: A randomized controlled trial. Medicine (Baltimore) 2017;96:e8644.

14. Romero A, Garcia JE, Joshi GP. The state of the art in preventing postthoracotomy pain. Semin Thorac Cardiovasc Surg 2013;25:116-24.

15. De Cosmo G, Aceto P, Gualtieri E, et al. Analgesia in thoracic surgery: review. Minerva Anestesiol 2009; 75:393-400.

Cite this article as: Matsutani N, Seki N. Effect of preoperative pregabalin in video-assisted thoracoscopic surgery. J Thorac Dis 2018;10(Suppl 33):S4028-S4030. doi: 10.21037/ jtd.2018.09.82
16. Gottschalk A, Cohen SP, Yang S, et al. Preventing and treating pain after thoracic surgery. Anesthesiology 2006; 104:594-600.

17. Ng A, Swanevelder J. Pain relief after thoracotomy: is epidural analgesia the optimal technique? Br J Anaesth 2007;98:159-62.

18. Bong CL, Samuel M, Ng JM, et al. Effects of preemptive epidural analgesia on post-thoracotomy pain. $\mathrm{J}$ Cardiothorac Vasc Anesth 2005;19:786-93.

19. Agarwal A, Gautam S, Gupta D, et al. Evaluation of a single preoperative dose of pregabalin for attenuation of postoperative pain after laparoscopic cholecystectomy. Br J Anaesth 2008;101:700-4.

20. Dirks J, Fredensborg BB, Christensen D, et al. A randomized study of the effects of single-dose gabapentin versus placebo on postoperative pain and morphine consumption after mastectomy. Anesthesiology 2002;97:560-4.

21. Field MJ, Holloman EF, McCleary S, et al. Evaluation of gabapentin and S-(+)-3-isobutylgaba in a rat model of postoperative pain. J Pharmacol Exp Ther 1997;282:1242-6.

22. Frampton JE, Scott LJ. Pregabalin: in the treatment of painful diabetic peripheral neuropathy. Drugs 2004;64:2813-20; discussion 21.

23. Ben-Menachem E. Pregabalin pharmacology and its relevance to clinical practice. Epilepsia 2004;45 Suppl 6:13-8.

24. Woolf CJ, Chong MS. Preemptive analgesia--treating postoperative pain by preventing the establishment of central sensitization. Anesth Analg 1993;77:362-79.

25. Aida S, Yamakura T, Baba H, et al. Preemptive analgesia by intravenous low-dose ketamine and epidural morphine in gastrectomy: a randomized double-blind study. Anesthesiology 2000;92:1624-30. 